\title{
Les Vies parallèles d'Alexandre Dumas, textes réunis par Charles Grivel
}

\section{Rita Severi}

\section{(2) OpenEdition}

1 Journals

\section{Edizione digitale}

URL: http://journals.openedition.org/studifrancesi/6701

DOI: ERREUR PDO dans/localdata/www-bin/Core/Core/Db/Db.class.php L.34 : SQLSTATE[HYO00]

[2006] MySQL server has gone away

ISSN: 2421-5856

\section{Editore}

Rosenberg \& Sellier

\section{Edizione cartacea}

Data di pubblicazione: 1 septembre 2010

Paginazione: 392-393

ISSN: 0039-2944

\section{Notizia bibliografica digitale}

Rita Severi, «Les Vies parallèles d'Alexandre Dumas, textes réunis par Charles Grivel», Studi Francesi [Online], 161 (LIV | II) | 2010, online dal 30 novembre 2015, consultato il 08 janvier 2021. URL: http:// journals.openedition.org/studifrancesi/6701 ; DOI: https://doi.org/10.4000/studifrancesi.6701

Questo documento è stato generato automaticamente il 8 janvier 2021.

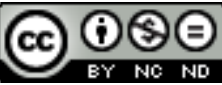

Studi Francesi è distribuita con Licenza Creative Commons Attribuzione - Non commerciale - Non opere derivate 4.0 Internazionale. 


\title{
Les Vies parallèles d'Alexandre Dumas, textes réunis par Charles Grivel
}

\author{
Rita Severi
}

\section{NOTIZIA}

AA. VV., Les Vies parallèles d'Alexandre Dumas, textes réunis par Charles GRIVEL, «Revue des Sciences humaines», n² 290, avril-juin, 2 /2008, pp. 240.

1 Questo numero monografico della rivista vuole mettere in luce il rapporto tra il poliedrico scrittore Alexandre Dumas e la sua biografia, attraverso una serie di «vite parallele» alle quali egli diede respiro in quanto si identificava con i suoi numerosissimi personaggi, come è ben evidente nel dramma Antony. Si tratta in questo caso della messa in scena dell' "homme fatal», in cui si assiste, secondo Fernando GUERRERo, allo spettacolo delle emozioni, tanto più vere quanto più sono teatrali. Dumas stesso ne era ben consapevole e persino nelle sue memorie, come puntualizza Didier BLONDE, egli si abbandona alla finzione letteraria. Gli era talmente congeniale che, come un furetto, secondo la definizione di Michel BRIX, riusciva a intrufolarsi dappertutto tra i generi della letteratura: dal dramma romantico, alle Impressions de voyage - sulle quali claude ScHopp si sofferma per chiarire le vicende di quattro giorni ad Algeri -, ai romanzi, ai feuilletons storici, agli adattamenti shakespeariani (Hamlet). Alexandre Dumas è anche l'«homme aux contes» che, nella carrellata panoramica di Francis MARCoIN, percorre tutte le tappe della scrittura, dalla tabulazione dei dati, alle causeries (sulle quali si soffermano Daniel COMPÈRE e Mélanie PAUTRAT, all'invenzione fantastica. Nel breve romanzo Catherine Blum (1854), Vittorio FRIGERIO evidenzia quanto Dumas usi una tecnica drammatica per parodiare la realtà del potere, sia profano (la Giustizia), sia sacro (la Chiesa), per approdare non alla descrizione realistica, ma ad un superamento della realtà stessa. D'altronde anche in un testo come La San Felice (1863-65), o in Joseph Balsamo (1846-48), o nei romanzi che rientrano nell'ambito "gotico», come Pauline (1838), analizzati, rispettivamente da Julie ANSELMINI, Isabelle CASTA e Angels SANTA, le 
discrepanze tra realtà storica e quella romanzesca sono talmente ampie da concludere che si tratta per lo più di «vite immaginarie». Le connotazioni simboliche dell'universo di Dumas sono contraddittorie e pregnanti. Charles GRIVEL, che offre un esempio d'analisi semantica sugli animali che popolano i romanzi, constata come il cane diviene un emblema che si trasforma a volte in lupo bianco, nero o grigio. Scrittore refrattario alle definizioni e alle collocazioni, Dumas ha avuto e gode tuttora di un ragguardevole Nachleben che spazia dagli adattamenti dei suoi romanzi alla fine del xIX secolo, studiati da Lise DUMASY, fino alle riduzioni in fotoromanzi che apparvero soprattutto in Italia sulle riviste Bolero e Grand Hôtel, commentate con spirito da Sylvette GIET. 